daß eine Zwischenschaltung einer Anreicherungskultur notwendig ist. Wir haben Seewasser durch Membranfilter filtriert, dann das Filter auf einen Filterkarton gelegt, der mit gealtertem Seewasser - supplementiert mit anorganischen Stickstoff- und Phosphorsalzen - getränkt war. Die Petrischale mit dem Filter wurde in einen Exsikkator gebracht, in dessen Fuß Petroleum eingefüllt worden war. Die Menge Petroleum war in den einzelnen Versuchen verschieden groß. Der Exsikkator wurde teilweise evakuiert. Nach wenigen Tagen Bebrütung zeigten sich Bakterienkolonien auf dem Filter. Im Nachtest ergab sich, daß es sich in allen Fällen um äußerst aktive Petroleumabbauer handelte. Oberimpfung von den Kolonien in Abbauflaschen zeigte bereits nach ca. 12 Stunden makroskopisch deutliche Petroleumabnahme und Bakterienvermehrung.

WALLHÄUSSER: Zur Isolation insbesonders von Mycobakterien kann man Mineralagar beimpfen und in einen Exsikkator mit Benzoldämpfen einbringen. Es ist jedoch ganz erstaunlich, daß Sie in solch kurzer Zeit einen Abbau hatten. Haben Sie auch andere Ole verwandt?

THon: Ja, zum Beispiel mit Heizöl M. Hier habe ich allerdings einen Oltropfen jeweils an die Seite des Filterkartons gegeben.

WALLHÄUSER: Ist es nicht möglich, daß aus dem Filterkarton etwas herausgelöst wurde, was als Kohlenstoffquelle dienen könnte? Können Sie mit Sicherheit einen Zelluloseabbau ausschließen?

THON: Das ist mit Sicherheit auszuschließen, denn wir haben stets Nachkulturen durchgeführt. Ohne Zufügung von Olen erhielten wir kein Wachstum, dagegen mit Olen eine äußerst rasche Vermehrung der Bakterien auf Kosten des Öls. Allerdings muß man diese Kontrollen sehr sorgfältig durchführen. In einigen. Fällen genügten bereits die in der Institutsluft vorhandenen Petroleumspuren, um einen schwachen Wuchs zu gestatten. Dies konnten wir jedoch leicht ausschalten, indem wir die Kontrollpetrischalen in Exsikkatoren einbrachten, die wir zunächst evakuierten und dann wieder belüfteten, wobei die zuströmende Luft durch Aktivkohle geleitet wurde.

WaLlHäUsSER: In den Kartons können auch Hemmstoffe enthalten sein.

Thon: Die Kartonscheiben wurden, bevor wir sie verwandten, von uns in Aqua destillata ausgiebig gewässert, um auch diese Möglichkeir auszuschließen.

BLOKKer: Ist etwas bekannt darüber, ob die Geschwindigkeit des Olabbaues in Süß-oder Salzwasser schneller ist?

WALLHÄUSSER: Ich habe keine Erfahrungen darüber.

KüHL: Vorausgesetzt, daß das Nährstoffangebot gleich ist, geht es im Seewasser schneller.

SCHӧвеRL: Sie sprachen vorhin von Enzym-Präparaten, die man zusetzt.

WaLLHÄUSSER: Wir haben Trockenkulturen von Desulfovibrio und auch Hormodendron zu öligem Erdboden zugesetzt, und wir haben den Eindruck, daß es etwas schneller geht. Die Gesamtkultur wurde gefriergetrocknet. Es wäre denkbar, daß man mit Trodkenmycel noch etwas ausrichten könnte, das mit Erde vermischt wird. Der Olabbau geht unter diesen Voraussetzungen etwas schneller, aber nicht schnell genug.

SснӧвеRL: Hierbei handelt es sich um Ganzzellen. Interessant wäre, ob Enzympräparate dieselbe oder eine schnellere Wirkung haben, denn es würden Permeabilitätsschwierigkeiten wegfallen.

WALLHäUSSER: Diese Frage wurde von uns bisher noch nicht untersucht.

\title{
Gewinnung von Eiweiß aus Erdöl und Erdgas durch Mikroorganismen
}

GUNKEL: In Frankreich, in Schottland und der UdSSR werden seit einer Reihe von Jahren Untersuchungen durchgeführt, um Protein für die tierische und menschliche Ernährung im großtechnischen Maßstab aus Erdöl und Erdgas herzustellen (z. B. Champagnat et al. 1963). 
WALLHäUSSER: Ich bin mit dieser Sache ziemlich vertraut; ich bin jedoch skeptisch. Dies ist mit Erdgas jedenfalls möglich, schwieriger ist es mit Erdöl. Von der BP sind entsprechende Versuche unternommen worden. In Deutschland stehen wir der Sache etwas skeptisch gegenüber, und zwar deswegen, weil größere Mengen Sulfitablauge bei den zellstoffverarbeitenden Industrien anfallen. Die Zellulosefabriken haben die Auflage bekommen, ihr Abwasser zu beseitigen. Sie könnten das sehr wohl beseitigen, wenn sie Hefe züchteten. Diese Hefe ist eine ausgezeichnete Nährhefe und wird in der Futterverwertung (Zusatz von ca. $5 \%$ ) gern eingesetzt, aber die Gestehungskosten sind viel zu hoch. Ich kann mir nicht vorstellen, daß bei der Beseitigung von Abwasser mit höheren Gestehungskosten zu rechnen ist, als wenn statt dieser Sulfitablauge irgendwelche Erdölrestprodukte verwendet werden. Dort müssen zusätzlich noch einige Prozesse eingeschleust werden, d.h. um die Olrückstände herauszuholen, muß die Hefe oder das Mycel nod einmal extrahiert werden. Infolgedessen wird ein solches Produkt immer teurer werden als die Hefe aus Sulfitablauge. Sicherlich werden diese Verfahren von Interesse sein in Ländern, die sehr viel Ol besitzen, und die auf der anderen Seite wenig Wald und wenig Sulfitablauge haben. Bei uns, wie auch im größten Teil von Europa - mit Ausnahme Frankreichs, das ja keine Wälder mehr hat und wohI auch keine große Zellstoffindustrie - besteht zunächst für ein solches Verfahren kein Interesse.

Gunkel: Mehr als die Hälfte der Menschheit ist unterernährt in bezug auf Eiweiß. Die Bevölkerungsexplosion, deren Zeuge wir sind, fordert, alle nur irgend möglichen Quellen für die Ernährung zu mobilisieren. Im Jahre 2000 rechnet man mit einer Gesamtbevölkerung der Erde von 6,6 Milliarden Menschen. Damit steigt der Gesamtbedarf an tierischem Eiweiß von jetzt 25 Millionen Tonnen auf 65 Millionen Tonnen (wenn man eine Steigerung der Tagesration der Einwohner der Entwicklungsländer auf 21 Gramm berücksichtigt). Sicherlich können noch weitere Reserven aus dem Meer mobilisiert werden. Inwieweit das möglich ist, ist noch eine offene Frage. Diese Eiweißlücke allein mit der Verarbeitung von Sulfitablauge schließen zu wollen, halte ich für illusorisch. Die mittelschweren Erdöldestillate könnten preisgünstig durch Hefen zu Protein verarbeitet werden, da durch sie gleichzeitig eine vorteilhafte Entparaffinierung durchgeführt würde, wodurch kültebeständige Dieselöle erhalten werden (vgl. CHampaGNAT 1967). CHEPIGo (1967) berichtete, daß man in einer 300- $\mathrm{m}^{3}$. Fermentieranlage heute schon täglich eine Tonne an eßbarem Eiweiß produzieren kann. Das entspricht dem Eiweißgehalt von 40 Rindern im Alter von 15 bis 18 Monaten.

WALLHÄUSSER: Es gibt aber auch andere Verfahren. Heute schon ist die fermentative Herstellung von Aminosäuren möglich; man kann z. B. aus ganz billigen Kohlenstoffquellen Aminosäuren herstellen. Nicht immer ist aber eine Fermentation das billigste Verfahren. Zum Beispiel kann man heute Lysin, das bis vor wenigen Monaten noch ausschließlich mit Hilfe von Micrococcus glutamicus in großen. Fermentern hergestellt wurde, weit billiger auf chemischem Wege synthetisieren. Und gerade an der Kostenfrage scheitern viele mikrobiologisch herstellbare Produkte.

Gunkes: Die billigsten Kohlenstoffquellen, die in großen Mengen vorliegen und leicht transportiert werden können, sind Erdgas und Rohöl.

WaLlHäusser: Sidher trifft das für Rohöl zu! Aber auf der anderen Seite können wir das Rohöl gerade in der Chemie weit besser verwenden. Es ist eine Sünde, daß man diesen Vorrat, der gar nicht so groß ist, auf diese Weise verschleudert!

GUNKEL: Wenn man hier von Verschleudern und Vergeuden spricht, so kann man am ehesten diesen Ausdruck für die Verbrennung von Kohlenwasserstoffen zur Energiegewinnung anwenden. Zumindest köunte ich mir vorstellen, daß unserer Generation dies von späteren Generationen vorgeworfen wird. Die Untersuchungen zur Proteingewinnung mit Hilfe von Mikroorganismen sind meiner Ansicht nach im höchsten Grad erfolgversprechend, und das Sammeln von Erfahrungen ist auf diesem Gebiet notwendig. Außerdem werden große Mengen Erdgas auf den Erdölfeldern abgefackelt, das ebenfalls als Kohlenstoffquelle für die mikrobielle Proteinsynthese dienen kann. Eine Nutzung dieser Kohlenwasserstoffe würde, im Gegenteil, eine Verschleuderung stoppen.

WALLHÄUSSER: Denken Sie nur daran, welche Methanmengen verlorengehen, die nicht genutzt 
werden! Bei der Abwasserbeseitigung ist man inzwischen dazu übergegangen, anfallendes Methan zu gewinnen. Denken Sie aber auch an die Müllverarbeitung; den Anfall organischer Produkte, die man auch in irgendeiner Weise weiterverwenden kann, insbesondere als Nährstoffe für Bakterien etc., oder denken Sie an die Massenzüchtung von Algen, wie sie z. B. im Institut für Kohlenstofforschung betrieben wird! Dies sind Fragen, die in Zukunft eine große Rolle spielen werden. Ich glaube, wir werden es in den nächsten Jahren jedenfalls nicht erleben, daß wir arbeitslos werden.

\section{Methodik der Bearbeitung sulfatreduzierender Bakterien und mikrobielle Aktivitäten in Gasspeichern}

GunKeL: Welche Kohlenstoffquellen verwenden Sie in Ihren 'Testbestecken, Herr WaLLeÄUsSER?

Wallhäusser: Nur Calciumlactat. Herr Professor BaArs äußerte übrigens, daß Calciumacetat auch sehr gut geeignet sei. Wir werden das prüfen. Manche Autoren sind der Meinung, Methan werde durch diese Organismen ausgenutzt. Wir wissen noch nicht, welcher Bestandteil vom Speichergas oder vom Erdöl als beste Kohlenstoffquelle dient. Es ist etwas enttäuschend zu sehen, wie wenig bei einem Abbauversuch im Boden geschieht. Andererseits kennen wir die ausgezeichnete Entwicklung dieser Desulfovibrionen in den Untertagegasspeichern, wo dex durch sie angerichtete Schaden erheblich ist. In einem Jahr fallen in einem Untertagegasspeicher mit 200 Millionen Norm $\mathrm{m}^{3}$ etwa 20 Tonnen Schwefelwasserstoff an. In Lacq (Südfrankreich) gibt es ein natürliches Erdgasvorkommen, das bis zu $15 \% \mathrm{H}_{2} \mathrm{~S}$ hat. Dort wird $\mathrm{H}_{2} \mathrm{~S}$ schon regelrecht gefördert. Man gewinnt daraus Schwefel, und ich habe ausgerechnet, daß ungefähr 16000 Jahre notwendig sind, um einen Schwefelgehalt von $15 \%$ zu erzielen. Früher hatte man sich vom Gesamtgeschehen ganz andere Vorstellungen gemacht; man hatte an eine Lagerung uber Jahrmillionen gedacht, bis ein solch hoher Schwefelwasserstoffgehalt zuwege gebracht ist. Weit gefehlt! Wir haben gerade durch diese Erfahrungen in den Untertagegasspeichern gesehen, $\mathrm{d} a ß$ dieses Geschehen zuweilen viel schneller abläuft, als man es wünscht, und zwar meist in negativer, manchmal aber auch in positiver Hinsicht. Denn auf der anderen Seite schlägt die Industrie ihr Kapital daraus, wenn sie beispielsweise Antibiotika oder Vitamine herstellt.

GUNKeL: Unter welchem Druck stehen die Bakterien in unterirdischen Gasspeichern bei 120 bis $140^{\circ} \mathrm{C}$ ?

WALLhÄUSSER: Der Druck beträgt etwa 100 bis $120 \mathrm{~atm}$.

GUNKeL: Sie kennen sicher die Arbeiten von ZoBeLL, der bei stark erhöhtem Druck eine erhöhte Resistenz gegen Hitze fand.

WallhäUsSER: Ich darf Thnen vorlesen, was ich dazu geschrieben habe: „Zur Erklärung seien einige amerikanische Untersuchungen angeführt. So konnte ZoBeli zeigen, daß diese Organismen hohe Temperaturen bei hohem Druck weit besser überstehen als beispielsweise bei $1 \mathrm{~atm}$." Wir Mikrobiologen sind immer etwas skeptisch gegenüber solch hohen Temperaturen und Drücken zugleich, denn wir wissen vom Autoklavieren: je höher der Druck wird, desto kürzer die Abtötungszeit. Bei dem geschilderten Fall hat man einen noch höheren Druck und noch höhere Temperaturen als beim Autoklavieren - und das sollen diese Bakterien überleben! Das ist schwer $z u$ verstehen.

Gunkel: Die Erklärung lautet wohl, daß denaturiertes Eiweiß einen größeren Raum einnimmt als lebendes Eiweiß und es bei sehr hohen Drucken, nach dem Gesetz des geringsten Zwanges, nicht zur Denaturierung kommt.

WaLlHäUSSER: Ja, genau!

GuNkel: Noch eine Frage betreffend die Grenzflächen zwischen OOl und Wasser und bakterielle Aktivität. LA Rrvì̀re (1955a, b) zeigte, daß von den Bakterien selbst während des Abbaues solche Emulgatoren gebildet werden. 